\title{
The Effect of Vulcanization Accelerator on the Properties of Porous Rubber
}

\author{
Kymbat S. Zhansakova*, \\ Gregory S. Russkikh and Evgeny N. Eremin \\ Omsk State Technical University \\ Omsk, Russian Federation
}

Received 12.12.2020, received in revised form 15.02.2021, accepted 11.03.2021

\begin{abstract}
This work is devoted to identifying the patterns of influence of the vulcanization accelerator $\mathrm{N}$-cyclohexyl-benzothiazyl-sulfenamide (CBS) on the technological, physico-mechanical, and thermophysical properties of vulcanizates based on styrene-butadiene rubber. It was found that a decrease in the content of the vulcanization accelerator decreases the maximum torque, and a noticeably longer time is required for optimum vulcanization in the absence of CBS. The thermal conductivity in vulcanizates increases with a decrease in the accelerator concentration due to changes in the structure and molecular mobility of kinetic units. Physico-mechanical indicators increase with a decrease in the concentration of CBS, this is due to a decrease in the apparent density of porous rubbers.
\end{abstract}

Keywords: vulcanization, rubber, porophore, vulcanization accelerator, sulfenamide C, pore formation.

\section{Влияние ускорителя вулканизации}

\section{на свойства пористых резин}

\author{
К. С. Жансакова, Г.С. Русских, Е.Н. Еремин \\ Омский государственный технический университет \\ Российская Федерачия, Омск
}

\begin{abstract}
Аннотация. Данная работа посвящена выявлению закономерностей влияния ускорителя вулканизации сульфенамида Ц на технологические, физико-механические и теплофизические свойства вулканизатов на основе бутадиен-стирольного каучука. Установлено, что снижение содержания ускорителя вулканизации уменьшает максимальный крутящий момент, а оптимальное
\end{abstract}

(C) Siberian Federal University. All rights reserved

This work is licensed under a Creative Commons Attribution-Non Commercial 4.0 International License (CC BY-NC 4.0).

* Corresponding author E-mail address: chemistbox@mail.ru 
время вулканизации заметно увеличивается при отсутствии сульфенамида Ц. Теплопроводность в вулканизатах увеличивается с уменьшением концентрации ускорителя из-за изменения структуры и молекулярной подвижности кинетических единиц. Физико-механические показатели растут с уменьшением концентрации сульфенамида Ц, это связано с уменьшением кажущейся плотности пористых резин.

Ключевые слова: вулканизат, каучук, порофор, ускоритель вулканизации, сульфенамид Ц, порообразование.

Цитирование: Жансакова, К.С. Влияние ускорителя вулканизации на свойства пористых резин / К. С. Жансакова, Г. С. Русских, Е.Н. Еремин // Журн. Сиб. федер. ун-та. Техника и технологии, 2021, 14(2). С. 215-221. DOI: 10.17516/1999494X-0302

\section{Введение}

Рецептуростроение резиновых смесей является сложным видом деятельности, направленным на улучшение свойств вулканизатов. В зависимости от требуемых характеристик можно получить материалы различного спектра назначения. Так, для получения пористых резин очень важно согласование скорости порообразования и оптимального времени вулканизации.

В качестве полимерной матрицы пористых резин используются каучуки общего и специального назначения. Кроме того, в состав вулканизата входят наполнители, вулканизующая система, стабилизирующая система и специальные компоненты [1].

Наполнители для пористых резин должны быть инертными или малоактивными, с небольшой удельной поверхностью. А вулканизующая система обычно состоит из вулканизующего агента, ускорителя и активатора вулканизации. Наиболее популярным вулканизующим агентом является сера. При определенном давлении и температуре она связывается с молекулами каучука, в результате происходит «сшивание» полимера и образуются серные «мостики». Продукт имеет сетчатую структуру и именуется эластомером (вулканизатом).

Для лучшего диспергирования ингредиентов и повышения степени сшивания каучука вводят различные активаторы вулканизации. Они могут быть органическими и неорганическими. В качестве органических активаторов используют жирные кислоты (стеариновая, олеиновая), а в качестве неорганических активаторов применяют оксиды металлов (цинка, магния) [2].

Отдельное внимание стоит уделить ускорителям вулканизации. Они более сложные по химическому составу, гораздо разнообразнее по классификации и играют одну из важных ролей в процессе вулканизации. Данный ингредиент способствует улучшению физико-механических свойств и ускорению процесса вулканизации. В зависимости от химической природы ускорители разделяются на следующие группы:

- дитиокарбоматы - продукты на основе солей дитиокарбаминовых кислот;

- тиурамсульфиды - продукты окисления дитиокарбоната натрия оксидами азота или продукты его взаимодействия с фосгеном;

- тиазолы - продукты конденсации анилина с сероуглеродом и серой в присутствии нитробензола;

- сульфенамиды - окисление продуктов взаимодействия меркаптобензтиазола с амином;

- гуанидины - продукты взаимодействия аммиака и производных тиомочевины;

- альдегидамины - продукты конденсации альдегидов жирного ряда с ароматическими или алифатическими аминами; 
- ксантогенаты - продукты взаимодействия сероуглерода со спиртами в присутствии щелочи [3].

Пропорции введения могут быть различными. В зависимости от содержания ускорителя и серы существуют три типа вулканизующих систем, представленных в табл. 1 [4]. В зависимости от сферы применения готового изделия для пористых резин могут использоваться все типы вулканизационных систем.

Содержания вулканизующего агента и ускорителя вулканизации варьируют относительно друг друга [5-8]. В то же время использованию в качестве ускорителя вулканизации сульфенамида Ц в пористых резинах уделяется явно недостаточное внимание.

Поэтому исследования влияния концентраций ускорителей вулканизации на свойства пористых резин актуальны.

Цель работы - выявление закономерностей влияния ускорителя вулканизации сульфенамида Ц на технологические, физико-механические и теплофизические свойства вулканизатов на основе бутадиен-стирольного каучука (СКМС-30АРКПН).

Объектами исследования являлись резиновые смеси и вулканизаты на основе бутадиенстирольного каучука с различным содержанием ускорителя вулканизации сульфенамида Ц. Рецепты резиновых смесей представлены в табл. 2. В качестве эталона был взят рецепт для бутадиен-стирольных пористых резин [9].

Таблица 1. Классификация вулканизующих систем

Table 1. Classification of vulcanization systems

\begin{tabular}{|l|c|c|c|}
\hline \multicolumn{1}{|c|}{ Тип системы } & $\begin{array}{c}\text { Содержание серы, } \\
\text { мас. ч. }\end{array}$ & $\begin{array}{c}\text { Содержание ускорителя, } \\
\text { мас. ч. }\end{array}$ & Ускоритель/сера \\
\hline Серная (стандартная) & $2,0-3,5$ & $1,2-0,4$ & $0,1-0,6$ \\
\hline Полуэффективная & $1,0-1,7$ & $3,5-1,2$ & $0,7-2,5$ \\
\hline Эффективная & $0,4-0,8$ & $5,0-2,0$ & $2,5-12,0$ \\
\hline
\end{tabular}

Таблица 2. Рецептура резиновой смеси

Table 2. Test compound formulation

\begin{tabular}{|c|c|c|c|c|}
\hline & Эталон & 1 & 2 & 3 \\
\hline Наименование ингредиента & \multicolumn{4}{|c|}{ Содержание, мас. ч., на 100 мас. ч. каучука } \\
\hline Каучук СКМС-30АРКПН & \multicolumn{4}{|c|}{100,0} \\
\hline Технический углерод П803 & \multicolumn{4}{|c|}{40,0} \\
\hline Оксид цинка, $\mathrm{ZnO}$ & \multicolumn{4}{|c|}{3,0} \\
\hline Сульфенамид Ц, CBS & 1,5 & 0 & 0,5 & 1,0 \\
\hline Пластификатор ХП-470А & \multicolumn{4}{|c|}{40,0} \\
\hline Диафен ФП & \multicolumn{4}{|c|}{2,0} \\
\hline Cepa & \multicolumn{4}{|c|}{2,5} \\
\hline Азодикарбонамид, ЧХЗ-21 & \multicolumn{4}{|c|}{6,5} \\
\hline Всего: & 195,5 & 194,0 & 194,5 & 195,0 \\
\hline
\end{tabular}


Изготовление резиновых смесей проводили на лабораторных вальцах типа LRMR$\mathrm{SC}-150 / \mathrm{O}$ с фрикцией валков 1:1,14, при температуре $50{ }^{\circ} \mathrm{C}$. Вулканизацию проводили в два этапа. На первом этапе проводили подпрессовку при давлении 0,25 МПа температуре $165{ }^{\circ} \mathrm{C}$ в течение 5 мин. Второй этап - непосредственно изготовление без приложения давления, температура $165^{\circ} \mathrm{C}$ в течение оптимального времени вулканизации. Для изготовления вулканизатов использовали гидравлический пресс марки Joos-Quality-Press.

Технологические свойства определяли с помощью безроторного виброреометра D-RPA 3000 при температуре $160{ }^{\circ} \mathrm{C}$ в течение 120 мин в соответствии с методикой ASTM D5289-17. Теплофизические свойства измеряли с применением прибора ИТС-1 в соответствии с методикой ГОСТ 7076. Для выявления физико-механических свойств использовали разрывную машину марки zwick/roell, скорость растяжения 500 мм в минуту, испытание проводили в соответствии с методикой ГОСТ 11721. Кроме того, устанавливали сопротивление сжатию образцов в соответствии с методикой ГОСТ 20014 при 50\%-ной степени сжатия от максимальной высоты образца, время выдержки образца в сжатом состоянии 60 +/- 6 с. Кажущуюся плотность определяли в соответствии с методикой ГОСТ 409.

\section{Результаты экспериментов и их обсуждение}

Результаты влияния содержания ускорителя вулканизации на свойства резиновых смесей и вулканизатов приведены в табл. 3 .

По результатам испытаний видно, что плотность сшивки полимера (разность крутящих моментов) максимальная в эталонном образце. Полученные данные коррелируют с содержанием ускорителя вулканизации и подтверждают наличие дополнительных связей между вулканизующей системой и каучуком. Время начала вулканизации характеризует способность резиновой смеси к преждевременной вулканизации. Полученные результаты не значительно различаются между собой.

Оптимальное время вулканизации самое большое у образца без ускорителя вулканизации, показатели остальных вулканизатов близки к эталонному образцу. Отсюда можно прийти к заключению, что для эффективного снижения оптимального времени вулканизации достаточно ввести небольшое количество (от 0,5 мас. ч.) сульфенамида Ц.

Исследуя полученные результаты теплопроводности, стоит отметить, что данное свойство зависит от марки каучука, марки наполнителя и его содержания, а также от количества оксида цинка [10]. Учитывая, что в данных вулканизатах варьировало только содержание ускорителя вулканизации, можно прийти к выводу, что структура и молекулярная подвижность кинетических единиц определяют теплофизические свойства образцов [11]. Поэтому с уменьшением содержания сульфенамида Ц теплопроводность увеличивается.

Уменьшение количества ускорителя вулканизации снижает условное напряжение при $300 \%$-ном удлинении, увеличивает прочность при растяжении и относительное удлинение при разрыве. Полученные данные коррелируют с результатами при сжатии. В то же время введение ускорителя вулканизации в обычных вулканизатах увеличивает физико-механические показатели. В случае пористых резин наблюдается противоположная картина.

Стоит учесть, что во время серной вулканизации без ускорителя образуются полисульфидные поперечные связи. С добавлением сульфенамида Ц, кроме полисульфидных, образу- 
Таблица 3. Результаты испытаний

Table 3. Results of testing

\begin{tabular}{|c|c|c|c|c|}
\hline & Эталон & 1 & 2 & 3 \\
\hline \multicolumn{5}{|l|}{ Технологические свойства } \\
\hline Минимальный крутящий момент, dH·м & 0,13 & 0,08 & 0,12 & 0,18 \\
\hline Максимальный крутящий момент, dH·м & 10,79 & 6,74 & 8,12 & 9,08 \\
\hline Разность крутящих моментов, $\mathrm{dH} \cdot \mathrm{M}$ & 10,66 & 6,66 & 8,00 & 8,90 \\
\hline Время начала вулканизации, мин & 5,80 & 6,54 & 7,18 & 6,44 \\
\hline Время достижения 50\%-ной степени вулканизации, мин & 14,57 & 14,55 & 13,54 & 12,18 \\
\hline Оптимальное время вулканизации (т90), мин & 24,07 & 32,09 & 22,32 & 19,26 \\
\hline Показатель скорости вулканизации, мин ${ }^{-1}$ & 5,47 & 3,91 & 6,61 & 7,80 \\
\hline \multicolumn{5}{|l|}{ Теплофизические свойства } \\
\hline Теплопроводность, Вт/м·К & 0,0851 & 0,1222 & 0,1502 & 0,1333 \\
\hline \multicolumn{5}{|l|}{ Физико-механические свойства } \\
\hline Условное напряжение при 100\%-ном удлинении, МПа & 0,23 & 0,28 & 0,22 & 0,21 \\
\hline Условное напряжение при 200\%-ном удлинении, МПа & 0,50 & 0,48 & 0,39 & 0,35 \\
\hline Условное напряжение при 300\%-ном удлинении, МПа & 0,84 & 0,71 & 0,58 & 0,51 \\
\hline Прочность при растяжении, МПа & 0,99 & 2,13 & 1,65 & 1,40 \\
\hline Относительное удлинение при разрыве,\% & 351,1 & 743,5 & 722,9 & 689,0 \\
\hline Сила сжатия, Н & 190,02 & 394,95 & 325,5 & 509,98 \\
\hline Сопротивление сжатию, МПа & 0,216 & 0,445 & 0,387 & 0,575 \\
\hline Кажущаяся плотность, кг/м³ & 381,87 & 506,52 & 521,69 & 593,37 \\
\hline
\end{tabular}

Таблица 4. Энергия связи для различных типов поперечных сшивок $[12,13]$

Table 4. Bond energy for various types of cross-linking [12, 13]

\begin{tabular}{|c|c|c|}
\hline Тип связи & Схематическое изображение & Энергия связи, кДж/моль \\
\hline Полисульфидная & $-\mathrm{C}-\mathrm{S}_{\mathrm{n}}-\mathrm{C}-$ & $<270$ \\
\hline Дисульфидная & $-\mathrm{C}-\mathrm{S}-\mathrm{S}-\mathrm{C}-$ & 270 \\
\hline Моносульфидная & $-\mathrm{C}-\mathrm{S}-\mathrm{C}-$ & 285 \\
\hline Углерод-углеродная & $-\mathrm{C}-\mathrm{C}-$ & 350 \\
\hline
\end{tabular}

ются еще и углерод-углеродные, моно- и дисульфидные поперечные связи. Такие типы сшивок характеризуются более высокими энергиями связи, указанными в табл. 4.

Полученные результаты показывают, что чем выше энергия связи, тем лучше протекает порообразование азодикарбонамида. Пористость эластомера увеличивается, и кажущаяся плотность уменьшается. 


\section{Заключение}

Установлено, что снижение содержания ускорителя вулканизации уменьшает максимальный крутящий момент, а оптимальное время вулканизации заметно увеличивается при отсутствии сульфенамида Ц.

Теплопроводность в вулканизатах увеличивается с уменьшением концентрации ускорителя из-за изменения структуры и молекулярной подвижности кинетических единиц.

Физико-механические показатели растут с уменьшением концентрации сульфенамида Ц, это связано с уменьшением кажущейся плотности образцов.

\section{Список литературы / References}

[1] Марк Дж., Эрман Б., Эйрич Ф. Каучук и резина. Наука и технология, Долгопрудный: Интеллект, 2011. 768 c. [Mark J., Erman B., Eirich F. Science and technology of rubber, Dolgoprudnyi, Intelligence, 2011, 768 p. (in Russian)]

[2] Рагулин В. В., Вольнов А. А. Технология шинного производства, М.: Химия, 1981, 264 с. [Ragulin V. V., Volnov A. A. Tire technology, Moscow, Chemistry, 1981. 264 p. (in Russian)]

[3] Новаков И.А., Вольсон С.И., Новопольцева О.М. Реологические и вулканизационные свойства эластомерных композииий, М.: Академкнига, 2006. 332 с. [Novakov I. A., Volson S.I., Novopoltseva O.M. Rheological and vulcanizing properties of elastomeric compositions, Moscow, Academic book, 2006, 332 p. (in Russian)]

[4] Datta R. N. Rubber curing systems. Rapra Rev. Rep., 2002, 12, 150 p.

[5] Boonkerd K., Deeprasertkul C., Boonsomwong K. Effect of sulfur to accelerator ratio on crosslink structure, reversion and strength in natural rubber, Rubber chemistry and technology. 2016, 89(3), 450-464

[6] Ghosh J., Ghorai S., Jalan A.K., Roy M., De.D. Manifestation of accelerator type and vulcanization system on the properties of silica-reinforced SBR/devulcanize SBR blend vulcanizates, J. Advances in polymer technology. 2018, 37, 2636-2650

[7] Lee J. Y., Ahn B., Kim W., Moon H., Paik H. J., Kim W. The effect of accelerator contents on the vulcanizate structures of SSBR/silica vulcanizates, J. Composite interfaces. 2016, 24(6), $1-15$

[8] Sainumsai W., Suchiva K., Toki S. Influence of sulphur crosslink type on the strain-induced crystallization of natural rubber vulcanizates during uniaxial stretching by in situ WAXD using a synchrotron radiation, Materials today: Proceedings. 2019, 17, 1539-1548

[9] Берлин А.А. Основы производства газонаполненных пластмасс и эластомеров, М.: Госхимиздат, 1954. 194 с. [Berlin A.A. Fundamentals of the production of gas-filled plastics and elastomers, Moscow, Goskhimizdat, 1954, 194 p. (in Russian)]

[10] Волков Д.П., Егоров А.Г., Мироненко М.Э. Теплофизические свойства полимерных композиционных материалов. Научно-технический вестник информационных технологий, механики и оптики, 2017, 17(2), 287-293 [Volkov D. P., Egorov A. G., Mironenko M. E. Thermo-physical properties of polymer composite materials, Scientific and Technical J. of Information Technologies, Mechanics, and Optics, 2017, 17(2), 287-293 (in Russian)]

[11] Шут Н.И., Лазоренко М.В., Сичкарь Т.Г. Взаимосвязь молекулярной подвижности и теплофизических свойств каучуков и вулканизатов. Каучук и резина, 1988, 8, 21-22 [Shut N. I., 
Lazorenko M. V., Sichkar T. G., The relationship of molecular mobility and thermophysical properties of rubbers and vulcanizates, J. Kauchuk $i$ Rezina 1988, 8, 21-22 (in Russian)]

[12] Востриков Д.С., Бочкарев Е.С., Димитров П.В., Ваниев М.А. Исследование влияния эффективных вулканизующих систем на свойства резин на основе бутадиен-нитрильного каучука. Известия Волгоградского государственного технического университета, 2019, 12 (235), 126-131 [Vostrikov D. S., Bochkarev E. S., Dimitrov P. V., Vaniev M. A. Study of the effect of effective vulcanizing systems on the properties of rubbers based on nitrile butadiene rubber, J. Bulletin of the Volgograd State Technical University, 2019, 12 (235), 126-131 (in Russian)].

[13] Ghorai S., Jalan A.K., Roy M., Das A., De.D. Turing of accelerator and curing system in devulcanized green natural rubber compounds, Polymer testing. 2018, 69, 133-145. 